\title{
In vivo evaluation of laser fluorescence performance using different cut-off limits for occlusal caries detection
}

Michele Baffi Diniz • Jonas de Almeida Rodrigues •

Andréia Bolzan de Paula •

Rita de Cássia Loiola Cordeiro

Published online: 14 August 2008

(C) Springer-Verlag London Ltd 2008

Erratum to: Lasers Med Sci

DOI 10.1007/s10103-008-0547-1

The second author's name was rendered wrongly. The correct citation is J. A. Rodrigues.

The online version of the original article can be found at http://dx.doi. org/10.1007/s10103-008-0547-1.

M. B. Diniz · J. A. Rodrigues $(\bowtie) \cdot$ R. d. C. L. Cordeiro

Department of Pediatric Dentistry,

Araraquara School of Dentistry,

São Paulo State University (UNESP),

Av. Humaitá 1680,

14801-903 Araraquara, SP, Brazil

e-mail: mibdiniz@hotmail.com

A. B. de Paula

Department of Dental Materials,

School of Dentistry of Piracicaba,

State University of Campinas (UNICAMP),

Av. Limeira, 901

13414-903 Piracicaba, SP, Brazil 